\title{
Using Interactive Teaching Methods when Forming Bachelors' Professional Competences in Management Studies
}

\author{
Shakina M.A. \\ National Research University Higher School of Economics Russia \\ Email: shakinama@hse.perm.ru \\ Georgieva N.Y. \\ National Research University Higher School of Economics, Russia \\ Email: ntlgrgv@yandex.ru
}

\section{Doi:10.5901/ajis.2013.v2n3p453}

\section{Abstract}

Russia's participation in the Bologna process led to the need to adapt training programs for bachelors, as well as teaching methods in accordance with the need to build bachelors' core competencies in management studies. In these circumstances it is important for both teachers and students to change the form of joint participation in the process of delivering and acquiring knowledge. The teacher cannot only translate knowledge, since in this case students should behave as independently functioning and decision-making subjects. Otherwise, they will not be able to master the necessary competencies and will not possess the qualities necessary for managers. One solution to this problem is using interactive teaching methods, such as roleplaying, case studies, videos, case studies, business games, design methods, and others. All these methods are aimed at the acquisition and interpretation of experience. The "Learning by Doing" approach, which is the basis for interactive technologies, opens great opportunities for semantic construction of the educational process and bringing it closer to real life. When doing the research, the authors developed a model of competencies that are formed during the "Developing Management Decisions" course. In the analysis of interactive methods we correlated competences that are to be formed at the end of the course and those formed by means of using interactive methods. Besides, the authors developed and tested some role-playing and simulation business games. We developed and tested the "Interactive Lecture" method; we formed a sufficient database of interactive methods that are obligatorily included in all seminars. Moreover, we conducted studies eliciting managerial qualities that undergraduate students possess before and after interactive classes. Finally, we reviewed and analyzed the dynamics of these changes.

\section{Introduction}

Recently, modern higher professional education in Russia is being deeply transformed in search of a creative approach. Analyzing the processes of computerization, globalization and "compression" of time and space allow identifying the causes of these changes. In the information society, the role of the teacher as a knowledge translator has been steadily declining. This one-way teaching process without students' feedback and their active participation indicates syllabus withdrawal from the teacher. According to the materials of the round-table conference on interactive teaching methods held at Moscow State University, the teacher's role in the environment where most students can gain knowledge from the Internet has to be changed. The teacher as a knowledge translator has to become a meaning translator. (Baidenko V, 2009)

When switching to the Federal State Educational Standard of Higher Professional Education (FSES HPE), many teachers of public higher education institutions have been confined within the strict requirements of the standard. One of the requirements to the conditions of the principle educational programs based on the FSES is an extensive use of active and interactive teaching forms in the educational process. Such forms, combined with extracurricular work, are believed to create and develop professional competences of undergraduate students most effectively. In the previous article (M.A. Shakina, N.Y. Georgieva, 2013) the authors formulated the main stages of developing the methodological base that forms key professional competencies. It includes the following steps:

1. Determining input and output competences forming the prerequisites a manager must have.

2. Selecting testing methods to determine some input competences and managerial qualities.

3. Conducting an entrance test, analyzing and interpreting the results. 
4. Selecting methods, forming competences and managerial qualities.

5. Applying the methods during the course "Making Managerial Decisions".

6. Monitoring maturity of the competences during the course.

7. Defining validity of the tests used.

8. Conducting an exit test, analyzing and interpreting the results.

9. Developing the mechanism of forming, monitoring and controlling maturity professional managerial competences.

The article mentioned above describes the results of the first three stages of the algorithm while the given article describes the fourth and fifth stages of this algorithm.

As noted above, modern society has become a favorable environment for complex structural changes such as forming new types of social relations and new forms of activity. Analyzing and interpreting these processes as well as relationships and activities require special teaching tools like interactive educational technologies that offer great opportunities to build a meaningful educational process. They are mostly used in terms of "understanding" and "experience" rather than "knowledge". In this regard the educational process, organized in an interactive mode, will serve as an effective means to develop a student's ability to comprehend and interpret. Those using interactive technologies will be able to analyze social phenomenon from within and gain personal experience as well as general experience, obtained for the entire group of students. An important feature of interactive educational forms is an emphasis on independent judgment and individual actions of each participant of this process. Students receive feedback from their group-mates or from the model, constructed according to certain laws, rather than the lecturer. Students act as those making decisions or exploring the model. Obviously, experience obtained in such a way has a specific persuasive power.

\section{Interactive Teaching Methods Review}

It is a long period since scientists and lecturers have developed numerous methods of communicating, developing skills, exchanging experience among the participants of the educational process. In her article, T. Kalinkina notes that all training methods can be roughly divided into three categories (Kalinkina T., 2010):

1. Focused on the teacher.

2. Individualized.

3. Interactive.

In the first case, the teacher is a dominant source of information with a tendency to using one-way communication chanel. This is what is called a "talking head" on television and "chalk, lesson and the monologue" when giving a traditional lecture. The first technique can be effective when a lecturer wants to convey a lot of information that has been synthesized from a variety of sources while the latter assumes the maximum degree of a student's self-management. Both methods can be used as part of extracurricular work for training specific practical techniques and skills or to develop the background information for the lecture or a seminar.

The third group includes interactive methods. Although they are not something completely innovative, interactive methods are not still widely used in the modern educational process and sometimes are not used by teachers at all. However, they are not of crucial importance, as their essence is in the interaction of all students, including the teacher.

Interactive teaching methods are an open discussion model, developing an ability to argue, to debate and resolve conflicts peacefully. Consequently, due to the use of these methods, students will have an increased interest to the course studied.

The basis for interactive approaches is interactive exercises and activities performed by students. Among the interactive approaches there are the following: creative activities, educational games (role playing, simulation, business and educational games), use of public resources (inviting a specialist, excursions), warm-up exercises, studying and revising new material, discussing complex and controversial issues and problems (e.g."Take the Position (range of opinions)," POPS-formula, projective techniques, "Change the Position", "Carousel", "The Talk Show Style Debate", debates, symposium), problem solving activities ("Incidents Analysis", "Negotiations and Mediation", "Stairs and Snakes"), the case method, interactive lectures and other techniques.

Let us formulate the basic features of the interaction:

1. Multi-voice activity: each member of the educational process can have their own point of view which differs from the others'.

2. Mental activity: organizing a mental activity which is an independent cognitive activity.

3. Meaning creation: conscious creation of a new meaning and viewing positions on the problems and situations. 


\section{Freedom of choice}

5. Creating a successful situation.

6. Reflection. Introspection. Self-esteem.

The abovementioned interactive methods are considered below in more detail.

When performing creative tasks, students are not only required to simply reproduce the information provided by the lecturer, but to be creative, since tasks contain elements of uncertainty and have, as a rule, more than one solution. Creative activities are supposed to encourage students. A variety of responses and an ability to find their own "correct" decision, based on their individual experience as well as on their colleague's, help students create the solid foundation for cooperation. The process of choosing the right creative task is rather complicated and time-consuming. It is to meet the following criteria:

$>$ it does not have a clear response or solution;

$>$ it is practical and useful for students;

$>$ it is linked to real life;

$>$ arises interested among students;

$>$ it serves educational objectives to the extent possible

$P$. Rabinowich and $E$. Akhurian reveal the effectiveness of multimedia technology, noting that they enrich the teaching process, involving most sensual elements of the student into the process of perceiving teaching information. These technologies could include videocases (Georgieva N.Y.,Shakina M.A, 2011).

Interactive and multimedia technologies can provide the environment for development and demonstration of core competencies, including primarily informational and communicative ones. Software products available, including readymade electronic textbooks and books, as well as their own developments, allow lecturers to improve the teaching process efficiency.

It is possible to highlight the main features of interactive and multimedia techniques:

$>$ ability to personalize the teaching process and adapt it to students' personal characteristics and needs;

$>$ ability to organize course material taking into consideration different ways of educative activities;

$>$ ability to clearly structure, consistently organize and compactly represent a large amount of educational information;

$>$ ability to enhance the visual perception and facilitate educational material assimilation;

$>$ ability to encourage students' cognitive activity (use of animation elements, computer-aided design). (Bagramyan E.R., Rabinovich P.D., 2012)

We find that the most interesting technique is the "Learning through Teaching" method, which was first developed and practically applied at Eichstätt University by Professor Dr. Jean-Paul Marten. Its purpose is to encourage students to learn and pass on their knowledge to their classmates.

The "Learning through Teaching" is a method under which both students and the lecturer prepare and conduct a workshop. This may relate to a number of episodes or even the whole seminar. The "Learning through Teaching" method is based on the three components: pedagogical-anthropological, teaching-theoretical and systematic, objective-directed and comprehensive.

In terms of the pedagogical-anthropological aspects, the "Learning through Teaching" method refers mainly to Maslow's hierarchy of needs. The task to transfer knowledge to others must satisfy the needs for reliability (selfawareness structure), social contact and social recognition as well as self-actualization, when it is necessary to mobilize as many intellectual resources as possible. The teaching- theoretical and systematic aspect is opposed to the traditional mode of educational material transmission. Based on the prepared but not yet systematized information on the lesson, students are challenged to convert this information by evaluating and systematizing knowledge. This process can take place only on the basis of intensive communication. From the point of view of the object-directed and comprehensive aspect, this method has long been eliminating the apparent contradiction existing among addiction (behavioral component), the material ratio (cognitive component) and authentic interaction (communicative component). In terms of comprehension, application of the "Learning through Teaching" method demands that the course material should be thought-provoking. The advantages of this method are the following: the material is worked through more intensively, students become more active, and in addition to the subject knowledge students acquire such competencies as an ability to work in a team, an ability to plan, and an ability to present and comment on the material.

However, the method could have certain disadvantages: 1) it takes time and extra effort when introducing the method; 2) there is some uncertainty when estimating students; 3 ) the front communication when "one says - the rest are silent" is maintained. 
When this method is used, students are given an opportunity to train thinking abilities and thereby produce knowledge which makes research and teaching harmoniously combined and thus, they match perfectly the university educational process requirements. This method is particularly able to differentiate traditional frequently detailed material and students' research (in a team). The "Learning through Teaching" method can be used in any university subject and in each group (particularly those that involve 15 to 35 members). (Maaren K,Krokfors L., 2008)

The "Omega-Mapping" method was developed by Vitaly Kolesnik, who states that this method helps to create fundamentally new ideas and find holistic solutions to complex problems. The "Omega-Mapping" concept was originated in the process of studying the links between creativity and motivation, and based on the ideas of Teilhard de Chardin and Edward de Bono. In fact, "Omega-Mapping" is an evolution model of transition from divergence to convergence. The method is based on the fact that a new idea not only helps to solve the problem, but also affects participants' view of the problem. Unlike most other methods of creating ideas, "Omega-Mapping" change of thinking could be built into the working process itself, which increases efficiency and depth of the idea development. "Omega-Mapping" is much more flexible in comparison with the mental maps, an imaging method of creative work.

The method is applicable for the following activities:

$>$ understanding complex problems, finding solutions, personal development;

$>$ for creative people: professional creation of ideas (advertising, marketing, promotion, design, architecture, photography, etc.);

$>$ for business owners, managers, marketing specialists: creation of new projects, products and services, problem-solving.

\subsection{Description}

The process of "Omega-Mapping" finding solutions involves two steps:

1. Fixing the existing views.

2. Creating a new concept and rebuilding the original assumptions in accordance with it.

To visualize this process the "omega-card" is used. In contrast to the usual mental map, it does not have a single central theme, but the two poles, indicating the initial and final view of the problem. The "omega-card" makes the process of creating a new concept vivid to the maximum extent.

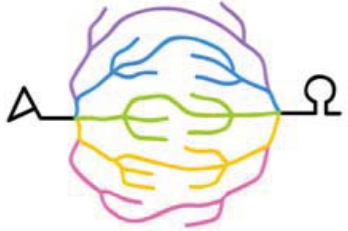

Figure 1. Omega-card scheme

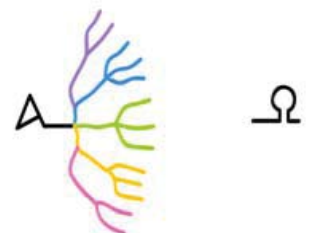

Figure 2. Alpha-tree

Omega-map is constructed between the alpha and the omega points. The "alpha" is our initial view, i.e. the point at which we begin our work. The "omega" is the final concept, i.e. the point to which the solution to our problem converges. The "omega" is not derivable from the original data in a rational way. Transition to this point is made by a jump or a shift in thinking, which is helped by the use of appropriate techniques of generating ideas. The jump is followed by restructuring the existing picture and creating a new one as well as creating rational links with the source data.

To visualize and structure the process of thinking about the problem the technique of mind mapping is used: thoughts are fixed in the form of keywords, located on the interconnected lines ("branches"). A group of lines coming from the "alpha-point" is called "alpha-tree", while a group of lines coming into the "omega-point" is called "omega-tree".

After finishing creation of the omega-card, it is necessary to fix the concept developed in order to better comprehend and clearly structure new ideas about the problem and its solutions. This can be done in different ways: by means of a project plan, a small text (mission, vision), a classical mental map, a presentation, etc. (Kolesnik)

\section{The Model of Management Bachelor's Professional Competences Formed when Studying "Development and Management Decisions" Course.}

At the first stage of the research the authors highlighted the professional competences generated when studying 
"Development Management Decisions" course. That is, we can provide a model of competencies and qualities that a graduate should possess. (M.A. Shakina, N.Y. Georgieva, 2013)

\section{Table 1}

\begin{tabular}{|c|c|c|}
\hline Organizational and managerial activity (OMA) & Informational and analytical activity (IAA) & Entrepreneurial activity (EA) \\
\hline PC-1, PC -18, PC -3, PC -19, PC -29, PC -16, PC -28 & PC -35, PC -47 & PC -48, PC -49, PC -50 \\
\hline
\end{tabular}

\subsection{Organizational and managerial activity}

PC-1: knows the main stages of the management thought evolution, outstanding managers' experience and knows how to match them with the circumstances of their own practices); PC-3: is able to offer organizational and managerial decisions and assess conditions and consequences of decisions made;

PC-14: considers the implications of management decisions and actions from the perspective of social responsibility;

PC-16: possesses methods of making strategic, tactical and operational decisions when managing organizations;

PC-18: possesses the tools of strategic management to develop the organizational strategy;

PC-19: is able to analyze the relationships among strategies of different levels in order to prepare balanced management decisions;

PC-29: is able to make decisions using corporate information systems;

PC-28: is able to develop management procedures and controls, knows reengineering methods of business process;

\subsection{Informational and analytical activity}

PC-35 is able to apply quantity and quality methods of analysis when making managerial decisions and to build economic, financial, organizational and management models;

PC-47 is able to analyze an organization's operational activity and serve as the basis for preparation of managerial decisions.

\subsection{Entrepreneurial activity}

PC-48 is able to find and evaluate new market opportunities and formulate a business idea etc.)

PC 49 is able to develop business plans for establishing and developing new organizations (activities, products,

PC 50 is able to assess the economic and social conditions of entrepreneurial activity.

The model of a graduate's qualities can be represented as follows:

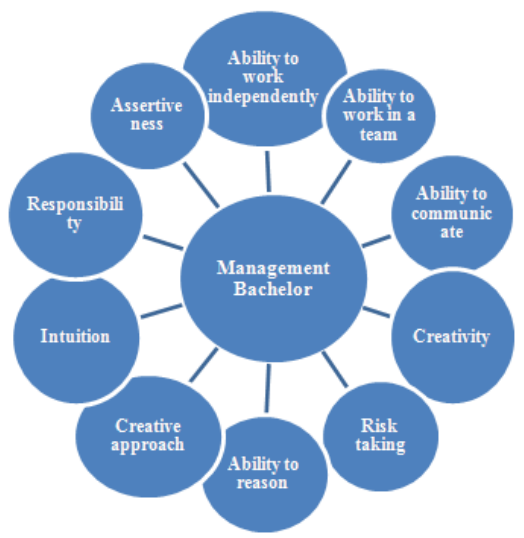

Fig. 3. Model of Management Bachelor's Qualities 
Let us range the qualities in numerical sequence for their further use when constructing matrices:

1. Intuition

2. Assertiveness

3. Ability to work in a team

4. Responsibility

5. Creativity

6. Ability to work independently

7. Risk taking

8. Ability to reason

9. Ability to communicate

The research conducted by the authors shows that the students who possess a high creative potential are more aimed at getting basic theoretical knowledge and a diploma, in particular, than acquiring possibility to practically apply the knowledge obtained. The students are not very risk averse; they tend to be assertive and willing to learn it. In addition, the survey conducted among the students shows that they have a vague idea of which features should managers possess and which personal qualities make them effective and successful. (M.A. Shakina, N.Y. Georgieva, 2013)

\section{Business Games, Developed by the Authors.}

In the process of creating a database of interactive methods the authors developed and implemented into the educational process such techniques as business game "Delphi Method" and role-playing game "The Court Method" that imitates the judicial proceedings. The court consider and analyze the causes of the problem and take a decision on the problem in question. During the game, students practice monologue skills, teamwork skills, presentation skills, an ability to reason, an ability to apply methods of investigating the problem, an ability to work with abundant information and a creative approach to business. For example, at one of the "court sessions" the students considered the problem of fuel crisis of summer 2011 in the Altai Area.

The business game "Delphi Method" is used when studying group methods of decision-making. During the game students master their ability to work independently and in a group, skills to analyze the situation, skills of statistical analysis and data visualization by means of using multimedia. In addition, the authors developed and applied a method of interactive lectures that are held in the computer lab. It is organized in such a way that the students are given only the theme structure and basic concepts. Then the students must find additional material on the subject independently and structure it, after which, within the same lesson, the students have to find information on an existing business and apply the theoretical aspects of the new theme when analyzing the case. For example, this type of lecture is used when studying the topic "Monitoring the decision-making process". This form of lectures develops skills to work in a team and independently, to work with large amount of information, to find the right information, analyze it and make the right decision within the limited period.

\section{Allocation of Interactive Methods, Skills and Qualities that are Generated in Management Bachelors.}

Exploring the possibility of using interactive methods when forming managers' professional competences and professional qualities when providing the "Developing Management Decisions" course, the authors generated a database including the methods developed and tested by Russian and foreign scientists and lecturers, and those developed and tested by the authors. They are the following:
1. Omega-mapping
2. Business game "Brainstorming"
3. Role-playing game "The Court Method"
4. Business game "Delphi Method"
5. Video Cases
6. Interactive lectures
7. The "Learning through Teaching" method.
8. Multimedia techniques
9. The method of writing projects
10. The method of writing scenarios
11. Business Game "Debate" (British format) 
When analyzing the above mentioned interactive techniques, the authors identified the qualities that a Management bachelor must have and the core competencies that are to be formed as a result of the "Development Management Decisions" course. The following matrices were compiled: "Interactive Methods - professional competence" matrix, "Interactive Methods - manager's professional qualities" matrix, "Interactive Methods - Professional competence - professional quality undergraduate management" matrix. Matrices are shown in the figures below.

\begin{tabular}{|l|c|c|c|c|c|c|c|c|c|c|c|}
\hline \multirow{2}{*}{\multicolumn{1}{|c|}{ PC }} & \multicolumn{10}{|c|}{ Interactive Methods } \\
\cline { 2 - 12 } & 1 & 2 & 3 & 4 & 5 & 6 & 7 & 8 & 9 & 10 & 11 \\
\hline $\begin{array}{l}\text { OMA } \\
\text { PC-1 }\end{array}$ & & & & & + & + & + & + & + & + & \\
\hline PC-3 & + & & + & + & + & & + & & + & + & \\
\hline PC-14 & + & + & + & + & + & & & & + & + & + \\
\hline PC-16 & + & & & + & + & & & & + & + & \\
\hline PC-18 & + & & & + & + & & + & + & + & + & \\
\hline PC-19 & & & & & + & & + & + & + & + & \\
\hline PC-28 & + & & & & + & & + & + & + & + & \\
\hline PC-29 & + & & & & + & + & & + & + & + & \\
\hline $\begin{array}{l}\text { IAA } \\
\text { PC -35 }\end{array}$ & + & & & + & + & + & + & + & + & + & \\
\hline PC -47 & + & & & & + & + & + & + & + & + & \\
\hline $\begin{array}{l}\text { EA } \\
\text { PC -48 }\end{array}$ & + & + & & + & + & & & & + & + & \\
\hline PC -49 & + & + & & + & + & & & + & + & + & \\
\hline PC -50 & + & + & + & + & + & & + & & + & + & \\
\hline
\end{tabular}

Fig 4. "Interactive Methods - professional competence" matrix

As seen from the table above, the most effective methods involved in the process of forming most professional competences are "Omega-mapping", "Delphi" method, video cases, "Learning Through Teaching" method, writing projects and scenarios.

\begin{tabular}{|c|c|c|c|c|c|c|c|c|c|c|c|}
\hline \multirow{2}{*}{ Prof. qualities } & \multicolumn{10}{|c|}{ Interactive methods } \\
\cline { 2 - 13 } & 1 & 2 & 3 & 4 & 5 & 6 & 7 & 8 & 9 & 10 & 11 \\
\hline 1 & + & & & & & + & & & + & + & \\
\hline 2 & + & & + & + & & & + & & + & & \\
\hline 3 & + & + & + & & + & + & & & + & + & + \\
\hline 4 & + & + & + & + & + & & + & & + & + & + \\
\hline 5 & + & + & + & + & + & + & + & + & + & + & + \\
\hline 6 & + & + & & + & + & + & + & + & & + & + \\
\hline 7 & + & + & & + & & & & & + & + & \\
\hline 8 & & & + & + & + & & + & + & & + & + \\
\hline 9 & & & + & & + & & + & & & + & + \\
\hline
\end{tabular}

Fig. 5. "Interactive Methods- manager's professional qualities" matrix

This matrix shows that such interactive methods as "Omega-mapping", Court method, Delfi method, video cases, "Learning through Teaching" method, multimedia techniques, writing projects and scenarios, business game "Debates" (UK format) fully embrace the qualities that, according to employers, a Management graduate must possess.

\begin{tabular}{|c|c|c|}
\hline $\begin{array}{c}\text { Interactive } \\
\text { methods }\end{array}$ & $\begin{array}{c}\text { Managerial } \\
\text { qualities }\end{array}$ & \multicolumn{1}{c|}{$\begin{array}{c}\text { Professional competences } \\
\text { (OMA) / ( (IAA) / (EA) }\end{array}$} \\
\hline 1 & $2,4.5,6,7$ & (PC-3, PC -14, PC -16, PC-18, PC-19, PC -28, PC-29) / (PC-35, PC-47) / (PC-48,PC-49, PC-50) \\
\hline 2 & $3,5,7,8,9$ & (PC-14, PC-48, PC- 49, PC-50) \\
\hline 3 & $2,3,4,5,8,9$ & (PC-3, PC-14, PC-16, PC-18, PC-19, PC-28, PC-29) / (PC-50) \\
\hline 4 & $2,4,5,6,7,8$, & (PC-3, PC-14, PC-16, PC-18, PC-19) / (PC-35) / (PC-48, PC-49, PC-50) \\
\hline 5 & $3,4,5.6,, 8,9$ & (PC-1, PC-3, PC-14, PC-16, PC-18, PC-28, PC-29) / (PC-47) / (PC-48, PC-49, PC-50) \\
\hline
\end{tabular}




\begin{tabular}{|c|l|l|}
\hline 6 & $1,3,5,6$ & (PC-1, PC-29) / (PC-35) / (PC-48, PC-49, PC-50) \\
\hline 7 & $2,4,5,6,8,9$ & (PC-1, PC-3, PC-18, PC-19, PC-28, PC-29) / (PC-35, PC-47) \\
\hline 8 & $5,6.8$ & (PC-1, PC-18, PC-19, PC-28, PC-29) / (PC-35, PC-47) / (PC-50) \\
\hline 9 & $1,2,3,4,5,7$ & (PC-1, PC-3, PC-14, PC-16, PC-18, PC-28, PC-29) / (PC-47) / (PC-48, PC-49, PC-50) \\
\hline 10 & $1,3,4,5,6,7.8,9$ & (PC-1, PC-3, PC-14, PC-16, PC-18, PC-28, PC-29) / (PC-47) / (PC-48, PC-49, PC-50) \\
\hline 11 & $1,2,3,4,6,7,9$ & PC-14 \\
\hline
\end{tabular}

Fig. 6. "Interactive Methods - Professional competence - professional quality undergraduate management" matrix

The matrix correlates interactive methods used by the authors in the "Development Management Solutions, Skills and Competencies of Managers" course.

\section{Findings}

To sum up, while implementing the fourth and fifth steps of the algorithm we analyzed capabilities of various tools used in the process of forming professional managerial competences and qualities; we created a competency profile of the Management Bachelor; we compiled matrices corresponding interactive methods, professional managerial competencies and qualities. In addition, we developed and tested new interactive methods. The result is a well-shaped base of interactive methods used when studying the "Developing Management Decisions" course.

\section{References}

Krokfors L., Maaranen K. Teacher as Integrators of Theory and Practice in Initial Teacher Education : Journal of Education for Teaching: JET: Intern. Research and Pedagogy. Birmingham, 2008. - Vol. 34, N 3. - P.207-222.

Georgieva N.Y., Shakina M.A. Monitoring Maturity of Bachelors' Professional Qualities and Competences in Management Studies. Economic and Social Development: Book of Proceedings of the 2nd International Scientific Conference. Paris, France, 5th April 2013.

Georgieva N.Y., Shakina M.A. Education Quality Improvement Via Creating and Introducing Modern Tools of Interactive Teaching /I International Journal of Arts and Sciences, 2011. - № 21. - C. 53-73

Bagramyan E.R., Rabinovich P.D. Guide in Interactive Technologies. BINOM. Knowledge Laboratory. - 2012. - 96 p.

Kolesnik V. Omega-Mapping. URL: http://dextera.ru/methods/omega-mapping

Johnson D. Teaching Methods. Teaching in Cooperation / D. Johnson, R. Johnson, E. Johnson-Holubek. - St. Petersburg: School of Economics. - 2001. $-256 \mathrm{p}$. 